\section{Lipid profile, apolipoprotein A-I and oxidative stress in professional footballers, sedentary individuals, and their relatives}

\author{
Perfil lipídico, apolipoproteína A-I e estresse oxidativo em jogadores \\ de futebol profissionais, indivíduos sedentários e seus familiares
}

Aline Margioti Zanella', Marcelo Arruda Nakazone',2,
Marcela Augusta Souza Pinhel', Dorotéia Rossi Silva Souza'

\begin{abstract}
Objective: To evaluate whether lipid profile (LP), apolipoprotein A-1 (apo A-I) and malondialdehyde (MDA) have any relationship with physical exercise by comparing the groups of footballers (FG) with sedentary individuals (CG) and their relatives (RFG and RCG). Subjects and methods: Twenty individuals from FG and CG, 60 from RFG, and 57 from RCG were studied. Results: FG showed lower levels of total cholesterol $(119.5 \pm 37.9 \mathrm{mg} / \mathrm{dL})$, LDL-cholesterol fraction (53.6 \pm 30.3$)$, apo A-I (116.7 \pm 11.9 ), and higher level of HDL-cholesterol fraction (HDLc) (49.7 $\pm 8.5)$ compared to RFG $(148.3 \pm 36.9, \mathrm{P}=0.02 ; 82.4 \pm 37.7, \mathrm{P}<0.01 ; 124.6 \pm 10.2, \mathrm{P}=0.03$; and $42.7 \pm 7.7, \mathrm{P}<0.01$; respectively). Moreover, FG had reduced levels of MDA $(101.0 \pm 77.0 \mathrm{ng} / \mathrm{mL})$ compared to CG $(290.0 \pm 341.0, P=0.03)$ and RFG $(209.9 \pm 197.5, P=0.04)$. Conclusions: These results suggest an association between physical exercise and lower levels of MDA in FG. Physical activity seems to promote beneficial effects on the LP regardless of the genetic influence considering HDLc levels. Arq Bras Endocrinol Metab. 2011;55(2):121-6
\end{abstract}

\section{Keywords}

Lipids; lipoproteins; oxidative stress; physical exercise; football player

\section{RESUMO}

Objetivo: Avaliar se perfil lipídico (PL), apolipoproteína A-1 (apo A-I) e malondialdeído (MDA) têm relação com atividade física comparando os grupos: jogadores de futebol (FG) com indivíduos sedentários (CG) e seus familiares. Sujeitos e métodos: Foram avaliados 20 indivíduos de FG e CG, além de 60 familiares de FG (RFG) e 57 de CG (RCG). Resultados: FG mostrou menores níveis (média $\pm \mathrm{DP}[\mathrm{mg} / \mathrm{dL}]$ ) de colesterol total $(119.5 \pm 37.9)$, LDL colesterol $(53.6 \pm$ 30.3), e apo A-I (116.7 \pm 11.9$)$, e maiores níveis de HDL colesterol (HDLc) (49.7 \pm 8.5$)$ comparado ao RFG (148.3 $\pm 36.9, P=0.02 ; 82.4 \pm 37.7, P<0.01 ; 124.6 \pm 10.2, P=0.03 ;$ e $42.7 \pm 7.7, P<0.01$; respectivamente). Além disso, o FG mostrou níveis reduzidos de MDA (101.0 \pm 77.0 [ng/mL]) comparado a CG $(290.0 \pm 341.0, P=0.03)$ e RFG $(209.9 \pm 197.5, P=0.04)$. Conclusões: Esses resultados sugerem que existe uma associação entre atividade física e níveis reduzidos de MDA em FG. $\mathrm{O}$ exercício físico parece promover efeitos benéficos no PL independente da influência genética considerando os níveis de HDLc. Arq Bras Endocrinol Metab. 2011;55(2):121-6

Descritores

Lipídios; lipoproteínas; estresse oxidativo; exercício físico; jogador de futebol
'Molecular Biology Department, Faculdade de Medicina de São José do Rio Preto (Famerp), São José do Rio Preto, SP, Brazil ${ }^{2}$ Cardiology and Cardiovascular Surgery Department, Famerp, São José do Rio Preto, SP, Brazil

\section{INTRODUCTION}

$\mathrm{O}$ ver the last three decades numerous studies have been conducted in relation to lipoprotein plasma levels and physical exercise in the prevention of onset of cardiovascular diseases $(1,2)$. Although regular exercise is known to decrease the risk of cardiovascular disease, studies suggest that exercise has little effect on total cholesterol (TC) and low density lipoprotein cholesterol fraction (LDLc), and only a minimal beneficial effect on high density lipoprotein cholesterol fraction (HDLc) (3-5), 
with opinions regarding the most effective type and the intensity of exercises remaining controversial (6). A better understanding of the mechanism of action of physical exercise on lipid profile is still needed (7-10).

Oxidative stress involves the production of reactive oxygen species (ROS) to an extent that overwhelms the antioxidant defense system (11). Although moderate exercise is associated with health benefits, high intensity aerobic physical exercises showed increases in the production of free radicals and oxidative stress. Increased production of ROS during strenuous physical exercise seems to contribute to tissue and cell damage including oxidative modification of the deoxyribonucleic acid (DNA) (12), thereby prejudicing athlete performance (13). In this context, the oxygenated compounds produced during free radical attack to membrane lipoproteins and polyunsaturated fatty acids, particularly to aldehydes such as malondialdehyde (MDA) and conjugated dienes, can be considered a marker of oxidative stress (14).

Although a growing number of studies confirm the benefits of physical activity, there is no consensus regarding which is the best type or intensity of exercise that should be practiced. In fact, results are controversial and in some populations, including Brazilian series, studies are scarce or non-existent. Therefore, it is important to identify factors that associated to physical exercise may influence the blood chemistry profile thus characterizing subgroups of individuals with respective risk factors. Hence, this study aimed at evaluating if the lipid profile, apolipoprotein A-I (apo A-I), and oxidative stress have any association with physical activity by comparing professional footballers to sedentary individuals and their respective relatives.

\section{MATERIALS AND METHODS}

\section{Subjects}

A total of 157 individuals with mixed ethnic backgrounds from southeastern Brazil who presented with genetic influence in equilibrium (15) were allocated into four groups in a transversal analytic study: Study Group (FG) - 20 male professional footballers of the América Futebol Clube team from the city of São José do Rio Preto (a top division team) aged 17-20 years, participating in an endurance exercise training for an imminent competition; Control Group (CG) - 20 male controls chosen from the general population, aged 17-20 years, who did not perform regular physical exercises on a daily basis (exercising three or more times a week) and without any other lipid metabolic disorder; Relatives of the Study Group (RFG) - 60 first-degree relatives (parents, brothers, and sisters) of the footballers, aged 12-67 years, and Relatives of the Control Group (RCG) - 57 first-degree relatives of the CG, aged 11-90 years. Smokers, alcoholics, individuals with liver, renal or thyroid diseases, hypertension, diabetes mellitus, family dyslipidemia, and individuals who had been using lipid-lowering drugs during the prior six months, at least, were precluded. Women were included only in the RFG and RCG groups, after comparison of age between the groups and aiming to prevent hormonal influence on the analysis of lipid profile. This study was approved by the Research Ethics Committee of Faculdade de Medicina de São José do Rio Preto, SP, Brazil (protocol number 4864/2003). Furthermore, every participant signed an informative form thereby indicating their consent.

\section{Exercise training and dietary consideration}

The study group included professional footballers, comprising of goalkeepers, defenders, and midfielders. They practiced daily aerobic and anaerobic exercising, twice a day (considering a total period of $6 \mathrm{~h}$ daily), for a period of six weeks, and were selected during an intensive physical exercise program with the objective of improving their fitness for the Paulista Championship of 2004. Carbohydrate-rich diets were supplied to the athletes (five meals a day), considering a higher energy expenditure during this pre-competition period.

\section{Blood chemistry measurements}

The individuals were referred for peripheral blood sampling to assess the levels of TC, HDLc, triglycerides (TG), apo A-I, glycemia, and MDA. Serum concentrations of TG and TC were defined by enzymatic colorimetric methods $(16,17)$. HDLc was determined by precipitation with dextran-magnesium chloride. LDLc and very low-density lipoprotein cholesterol fraction (VLDLc) were calculated by the Friedewald formula for TG levels below $400 \mathrm{mg} / \mathrm{dL}$ (18). Reference values were those recommended by the III Brazilian Guidelines on Dyslipidemias and Guidelines on Atherosclerosis Prevention from the Atherosclerosis Department of the Brazilian Cardiology Association (19). Plasma glycemia levels were achieved using the enzymatic method with oxidase glucose. The reference value for glycemia was 60 to $99 \mathrm{mg} / \mathrm{dL}$ according to the Expert Committee on the Diagnosis and Classification of Diabetes Mellitus 
(20). The technique used to analyze MDA was based on the thiobarbituric acid (TBA) reaction in low $\mathrm{pH}$ and high temperature (21), considering normal levels for serum and plasma values from zero to $440 \mathrm{ng} / \mathrm{mL}$. Measurement of Apo A-I was carried out using the immunoturbidimetry method (22), considering reference values of $94-178 \mathrm{mg} / \mathrm{dL}$ in men and of $101-199 \mathrm{mg} / \mathrm{dL}$ in women. Height and weight were measured using an anthropometric scale and the values obtained were used to calculate body mass index (BMI) by using the formula BMI = weight $(\mathrm{kg}) /$ height $^{2}\left(\mathrm{~m}^{2}\right)(23)$.

\section{Statistical analysis}

Lipid profile, apo A-I and MDA values were compared between the footballer and control groups, footballers and their first-degree relatives, controls and their relatives, and the relatives of footballers with the relatives of the controls using the two-sample student $t$-test and the matched $t$-test in respect to age with a $95 \%$ confidence interval. The frequencies of individuals with altered levels of lipid profile, apo A-I, and MDA were compared among the groups by applying the Fisher exact test and demographic data were compared by the Chi-square test. Pearson's Correlation was calculated for the variables: LDLc, HDLc, VLDLc, TC, glycemia, apo A-I, MDA, and BMI. Multivariate logistic regression analysis was performed for oxidative stress (MDA) as the dependent variable and blood chemistry profile, age, sedentary life style, and smoking as independent variables. Significance was defined as $\mathrm{P}<0.05$.

\section{RESULTS}

Demographic data such as weight and BMI, respectively, did not differ between FG $(70.2 \pm 8.0$ and $22.4 \pm$ $1.4)$ and $C G(74.0 \pm 12.9$ and $24.0 \pm 3.5)$, nor between RFG $(68.9 \pm 17.4$ and $24.7 \pm 4.9)$ and RCG $(68.8$ $\pm 16.2 \mathrm{~kg}$ and $\left.24.8 \pm 4.7 \mathrm{~kg} / \mathrm{m}^{2}\right)$. Table 1 demonstrates the mean values for lipid profile, apo A-I, MDA, and glycemia in FG, controls, and their respective first-degree relatives. In every group the mean values were within reference range for all variables except for the level of TG in footballers, whose mean value showed increases according to age distribution (147.0 \pm 134.0 $\mathrm{mg} / \mathrm{dL}$ ); however, without statistical significance when compared to $\mathrm{CG}$ with a mean value within the reference range $(92.8 \pm 64.1 \mathrm{mg} / \mathrm{dL}, \mathrm{p}=0.12)$.

RFG presented with mean TC and LDLc levels significantly higher $(148.3 \pm 36.9 \mathrm{mg} / \mathrm{dL}$ and $82.4 \pm 37.7$ $\mathrm{mg} / \mathrm{dL}$, respectively) compared to $\mathrm{FG}(119.5 \pm 37.9$ $\mathrm{mg} / \mathrm{dL}, \mathrm{p}=0.02$ and $53.6 \pm 30.3 \mathrm{mg} / \mathrm{dL}, \mathrm{p}<0.01$; respectively). However, the values of both groups were within reference ranges. On the other hand, FG presented with significantly higher levels of HDLc (49.7 $\pm 8.5 \mathrm{mg} / \mathrm{dL}$ ) when compared to their relatives $(42.7$ $\pm 7.7 \mathrm{mg} / \mathrm{dL}, \mathrm{p}<0.01)$. The analysis between FG and sedentary life style individuals from RFG reinforces the dominant influence of exercise activity on the blood chemistry profile of our sample, since it confir$\mathrm{ms}$ the evidenced differences. Among RCG, significantly higher levels of TG $(126.3 \pm 44.7 \mathrm{mg} / \mathrm{dL})$ were observed compared to the CG $(92.8 \pm 64.1 \mathrm{mg} / \mathrm{dL}$; $\mathrm{p}=0.04)$, nevertheless the mean values of both groups were within reference range. A comparative analysis also showed significantly higher LDLc levels in the RFG $(82.4 \pm 37.7 \mathrm{mg} / \mathrm{dL})$ compared to RCG $(61.2$ $\pm 23.0 \mathrm{mg} / \mathrm{dL}, \mathrm{p}<0.01)$ although both mean values were within reference range.

The mean levels of apo A-I, MDA and glycemia were also within the desired range in all of the groups. However, FG had a significantly lower mean value for apo A-I $(116.7 \pm 11.9 \mathrm{mg} / \mathrm{dL})$ compared to RFG (124.6 $\pm 10.2 \mathrm{mg} / \mathrm{dL}, \mathrm{p}=0.03)$. Additionally, they presented with a significantly lower mean value for MDA (101.0 $\pm 77.0 \mathrm{ng} / \mathrm{mL})$ compared to their relatives $(209.9 \pm$ $197.5 \mathrm{ng} / \mathrm{mL}, \mathrm{p}$-value $=0.04)$ and to CG $(290.0 \pm$ $341.0 \mathrm{ng} / \mathrm{mL} ; \mathrm{p}=0.03)$. Nevertheless, FG had higher glycemia levels $(90.2 \pm 12.2 \mathrm{mg} / \mathrm{dL})$ compared to $\mathrm{CG}$ $(74.1 \pm 14.7 \mathrm{mg} / \mathrm{dL}, \mathrm{p}<0.01)$.

The frequency of individuals with altered values for lipid profile, glycemia, apo A-I, and MDA are shown in table 2. Similarity between the groups except for the significantly higher frequency of reduced levels for HDLc in RFG $(48.3 \%)$ compared to FG themselves $(15 \%, \mathrm{p}<0.01)$ was noted. Also noted was a significantly higher frequency in the altered levels of TC and LDLc in RFG (20\% for both) compared to the RCG $(5.3 \%, \mathrm{p}=0.03$ and $3.5 \%, \mathrm{p}<0.01$; respectively). On the other hand, altered levels of VLDLc and TG were more frequently observed in RCG $(29.8 \%$ and $31.6 \%$, respectively) compared to RFG (13.3\%, p $=0.04$ and $15.0 \%, \mathrm{p}=0.05$; respectively). Higher glycemia levels were observed in $25 \%$ of $\mathrm{FG}$.

Multivariate logistic regression analysis considering MDA as a dependent variable and the parameters as independent variables demonstrated statistical significance for obesity $(\mathrm{p}=0.04)$ and sedentary life style $(\mathrm{p}=0.02)$ associated with levels of MDA (Table 3). Calculations produced the logit formula $\mathrm{y}=-1.946927-0.059562$ 
Table 1. Distribution of blood chemistry profile in professional footballers (FG), controls (CG), and their respective first-degree relatives (RFG and RCG)

\begin{tabular}{|c|c|c|c|c|c|c|c|c|}
\hline $\begin{array}{l}\text { Blood chemistry } \\
\text { Profile }\end{array}$ & $\begin{array}{c}\mathrm{FG} \\
(\mathrm{N}=20)\end{array}$ & $\begin{array}{c}\text { CG } \\
(N=20)\end{array}$ & $\begin{array}{c}\text { RFG } \\
(\mathrm{N}=60)\end{array}$ & $\begin{array}{c}\text { RCG } \\
(\mathrm{N}=57)\end{array}$ & $\begin{array}{l}\text { P-value } \\
\text { FG X CG }\end{array}$ & $\begin{array}{c}\text { P-value } \\
\text { FG } \times \text { RFG }\end{array}$ & $\begin{array}{l}\text { P-value } \\
\text { CG } \times \text { RCG }\end{array}$ & $\begin{array}{c}\text { P-value } \\
\text { RFG X RCG }\end{array}$ \\
\hline $\mathrm{TC}(\mathrm{mg} / \mathrm{dL})$ & $119.5 \pm 37.9$ & $129.7 \pm 44.5$ & $148.3 \pm 36.9$ & $132.2 \pm 24.3$ & 0.44 & 0.02 & 0.81 & 0.08 \\
\hline $\mathrm{HDLC}(\mathrm{mg} / \mathrm{dL})$ & $49.7 \pm 8.5$ & $46.3 \pm 14.4$ & $42.7 \pm 7.7$ & $46.9 \pm 10.0$ & 0.37 & $<0.01$ & 0.87 & 0.09 \\
\hline LDLc (mg/dL) & $53.6 \pm 30.3$ & $65.0 \pm 31.9$ & $82.4 \pm 37.7$ & $61.2 \pm 23.0$ & 0.26 & $<0.01$ & 0.61 & $<0.01$ \\
\hline VLDLC (mg/dL) & $21.8 \pm 18.3$ & $18.5 \pm 12.8$ & $21.2 \pm 9.2$ & $24.0 \pm 9.0$ & 0.45 & 0.84 & 0.07 & 0.10 \\
\hline $\mathrm{TG}(\mathrm{mg} / \mathrm{dL})$ & $147.0 \pm 134.0$ & $92.8 \pm 64.1$ & $102.5 \pm 45.5$ & $126.3 \pm 44.7$ & 0.12 & 0.18 & 0.04 & 0.05 \\
\hline Apo A-I (mg/dL) & $116.7 \pm 11.9$ & $123.0 \pm 21.9$ & $124.6 \pm 10.2$ & $125.2 \pm 12.9$ & 0.27 & 0.03 & 0.64 & 0.94 \\
\hline MDA (ng/mL) & $101.0 \pm 77.0$ & $290.0 \pm 341.0$ & $209.9 \pm 197.5$ & $298.7 \pm 211.4$ & 0.03 & 0.04 & 0.90 & 0.04 \\
\hline Glycemia (mg/dL) & $90.2 \pm 12.2$ & $74.1 \pm 14.7$ & $79.7 \pm 34.4$ & $83.1 \pm 35.4$ & $<0.01$ & 0.21 & 0.26 & 0.70 \\
\hline
\end{tabular}

$\mathrm{N}$ : number of individuals; TC: total cholesterol; HDLc: high-density lipoprotein cholesterol fraction; LDLc: low-density lipoprotein cholesterol fraction; VLDLc: very low-density lipoprotein cholesterol fraction; TG: triglycerides; apo A-l: apolipoprotein A-I; MDA: malondialdehyde.

$P$-value in reference to $t$-test.

Table 2. Professional footballers (FG), controls (CG), and their respective first-degree relatives (RFG and RCG), considering demographic data and altered blood chemistry profile

\begin{tabular}{|c|c|c|c|c|c|c|c|c|c|c|c|c|}
\hline \multirow{2}{*}{ Variables } & \multicolumn{2}{|c|}{$\mathbf{F G}$} & \multicolumn{2}{|c|}{ CG } & \multicolumn{2}{|c|}{ RFG } & \multicolumn{2}{|c|}{ RCG } & \multirow{2}{*}{$\begin{array}{l}\text { P-value } \\
\text { FG x CG }\end{array}$} & \multirow{2}{*}{$\begin{array}{l}\text { P-value } \\
\text { FG x RFG }\end{array}$} & \multirow{2}{*}{$\begin{array}{l}\text { P-value } \\
\text { CG x RCG }\end{array}$} & \multirow{2}{*}{$\begin{array}{c}\text { P-value } \\
\text { RFG x RCG }\end{array}$} \\
\hline & $\mathbf{N}$ & $\%$ & $\mathbf{N}$ & $\%$ & $\mathbf{N}$ & $\%$ & $\mathbf{N}$ & $\%$ & & & & \\
\hline Obesity & 0 & 0 & 2 & 10.0 & 8 & 13.3 & 10 & 17.5 & 0.47 & 0.20 & 0.66 & 0.71 \\
\hline Smoking & 0 & 0 & 2 & 10.0 & 13 & 21.7 & 4 & 0.7 & 0.47 & 0.05 & 0.67 & 0.05 \\
\hline Sedentary life style & 0 & 0 & 20 & 100.0 & 36 & 60.0 & 38 & 66.7 & $<0.01$ & $<0.01$ & $<0.01$ & 0.58 \\
\hline TC & 2 & 10.0 & 3 & 15.0 & 12 & 20.0 & 3 & 5.3 & 1.00 & 0.18 & 0.50 & 0.03 \\
\hline HDLC & 3 & 15.0 & 5 & 25.0 & 29 & 48.3 & 18 & 31.6 & 0.69 & $<0.01$ & 0.78 & 0.09 \\
\hline LDLC & 2 & 10.0 & 2 & 10.0 & 12 & 20.0 & 2 & 3.5 & 1.00 & 0.28 & 0.50 & $<0.01$ \\
\hline VLDLC & 2 & 10.0 & 2 & 10.0 & 8 & 13.3 & 17 & 29.8 & 1.00 & 0.08 & 1.00 & 0.04 \\
\hline$T G$ & 5 & 25.0 & 3 & 15.0 & 9 & 15.0 & 18 & 31.6 & 0.69 & 0.24 & 0.32 & 0.05 \\
\hline Apo A-I & 0 & 0 & 1 & 5.0 & 3 & 5.0 & 4 & 7.0 & 1.00 & 1.00 & 0.57 & 0.71 \\
\hline MDA & 0 & 0 & 6 & 30.0 & 11 & 18.3 & 22 & 38.6 & 0.02 & 0.59 & 0.06 & 0.02 \\
\hline Glycemia & 5 & 25.0 & 1 & 5.0 & 4 & 6.6 & 8 & 14.0 & 0.18 & 0.26 & 0.04 & 0.23 \\
\hline
\end{tabular}

$\mathrm{N}$ : number of individuals; TC: total cholesterol; HDLc: high-density lipoprotein cholesterol fraction; LDLc: Iow-density lipoprotein cholesterol fraction; VLDLc: very low-density lipoprotein cholesterol fraction; TG: triglycerides; apo A-I: apolipoprotein A-I; MDA: malondialdehyde.

P-value in reference to Chi-square test for demographic data or P-value in reference to Fisher exact test for altered levels of blood chemistry profile.

Table 3. Multivariate logistic regression analyses, considering malondialdehyde (MDA) as an independent variable and other parameters as dependent variables

\begin{tabular}{lcc}
\hline Intercept & $\mathrm{b} 0=-1.946927$ & $\mathrm{p}<0.01$ \\
Age & $\mathrm{b} 1=-0.059562$ & $\mathrm{p}=0.90$ \\
TC & $\mathrm{b} 2=-1.562404$ & $\mathrm{p}=0.26$ \\
LDLC & $\mathrm{b} 3=-1.139409$ & $\mathrm{p}=0.44$ \\
HDLC & $\mathrm{b} 4=0.263374$ & $\mathrm{p}=0.54$ \\
VLDLC & $\mathrm{b} 5=14.430107$ & $\mathrm{p}=0.99$ \\
TG & $\mathrm{b} 6=-14.096693$ & $\mathrm{p}=0.99$ \\
Glycemia & $\mathrm{b} 7=0.244552$ & $\mathrm{p}=0.63$ \\
Apo-Al & $\mathrm{b} 8=0.708706$ & $\mathrm{p}=0.40$ \\
Obesity & $\mathrm{b} 9=1.231918$ & $\mathbf{p}=\mathbf{0 . 0 4}$ \\
Smoking & $\mathrm{b} 10=-0.044557$ & $\mathrm{p}=0.95$ \\
Sedentary life style & $\mathrm{b} 11=1.06352$ & $\mathbf{p}=\mathbf{0 . 0 2}$ \\
\hline
\end{tabular}

B: logit; TC: total cholesterol; LDLc: low density lipoprotein cholesterol fraction; HDLc: high density lipoprotein cholesterol fraction; VLDLC: very low density lipoprotein cholesterol fraction; TG: triglycerides; Apo A-l: apolipoprotein A-I.

age +1.562404 TC -1.139409 LDL + 0.263374 HDL +14.430107 VLDL - 14.096693 TG +0.244552 glyce$\mathrm{mia}+0.708706$ Apo A-I +1.231918 obesity -0.044557 smoking +1.06352 sedentary life style, in which logit = logit 0 utilized in the estimation of individual risk for increases in MDA levels associated to obesity and sedentary life style. As only obesity and sedentary life style were statistically significant the logit formula $y=1.946927$ +1.064207 obesity +1.02999 sedentary life style was indicated to calculate the risk. Smoking, an important risk factor for oxidative stress and lipid profile, did not influence blood chemistry profile in our sample.

\section{DISCUSSION}

Our study indicates that professional footballers and controls do not differ in their lipid profiles as reported by Petridou and cols. (24) considering individuals with similar body fat. The data also show lower levels of TC, LDLc, and apo A-I and higher levels of HDLc in athletes compared to their relatives. However, considering apo A-I values the influence of physical activity remains controversial $(4,25)$ depending on type and intensity of 
exercising with differences seen between men and women. In addition, the analysis for HDLc proposed by Jafari and cols. (26) and Ribeiro and cols. (27) considering the role of HDL subparticle species (as prebeta 1-HDL) in reverse cholesterol transport could be useful to demonstrate the effects on HDLc metabolism as it pertains to coronary artery disease risk reduction, data not available from the current study. However, the reduced levels of HDLc observed particularly in RFG (48\%), compared to $15 \%$ of FG, highlight the effect of physical activity on HDLc levels. The higher HDLc levels in FG compared to the other two groups, with a significant difference in respect to their relatives (of which $60.0 \%$ were sedentary), reinforce this hypothesis (28). In this view, regular intensive physical exercise had widespread beneficial effects on baseline lipid levels in spite of genetic influence (29), confirming that heritable factors partly determine lipid profile responses to regular exercise (30).

In our series, as suggested by some studies, physical exercise had little influence on TC and LDLc levels (35 ), considering that the values in FG and CG were similar. In addition, footballers, controls, and their respective first-degree relatives presented with mean values for lipid profile within the reference range except for TG, whose mean level in FG was greater than the reference range. Footballers had been training intensively six hours a day for a period of six weeks with the objective of improving their fitness for an imminent competition. For this reason, they were on a carbohydrate-rich diet of five meals per day aiming to supply substrate for the higher energy expenditure during the pre-competition period. Among athletes, the intake of a carbohydrate-rich diet is common to sustain prolonged periods of exercising without the onset of fatigue $(31,32)$. This practice may increase plasma TG levels $(33,34)$ and reduce the efficiency of its removal (35). The fact that carbohydrate-rich diets often increase plasma TG has led some to question the wisdom of such diets as the hypertriglyceridemia is considered an independent risk factor for coronary artery disease (36).

In this study, $25 \%$ of the footballers had higher TG levels. This result is in agreement with the study of Leon and Sanchez (3), who associated a high level of TG with intense physical activity in basketball players, swimmers, and long-distance runners, compared to sedentary individuals. These authors concluded that increased levels of lipids are directly related to the intensity and duration of physical activity and acute exercises may induce change in lipid parameters, enhancing the chronic effects of physical exercise. On the other hand, Hernández-Torres and cols. (10) showed that TG was not modified by any kind of exercise in contrast with TC and cholesterol fractions. In this case, they concluded that lipid profile could be changed if the exercise was practiced continuously or intermittently, considering the influence of aerobic fitness. In addition, in the current study, FG presented with a mean level of glycemia within reference range as in the other groups, however, with a higher value. Five of them (25\%) had glycemia levels higher than the limit value, ranging from 100.0 to $104.0 \mathrm{mg} / \mathrm{dL}$.

It is important to note that several investigators have demonstrated that high-carbohydrate diets are associated with the development of insulin resistance, and increased serum TG and insulin levels $(34,37)$. It is well known that increases in intracellular deposits of TG in the muscle, liver, and pancreas, predisposes individuals to diabetes as it acts on glucose mechanism, interfering in the release of insulin (38). Physical activity has many well-established health benefits (1), but intensive exercises increase muscle oxygen influx and can lead to increased oxidative injury (13). Increased lipid peroxidation is thought to be a consequence of oxidative stress which occurs when the dynamic balance between the prooxidant and antioxidant mechanisms is impaired $(11,39)$. In the current study, oxidative stress was evaluated by serum analysis of MDA (14), a lipid peroxidation product, for which mean values for all groups were within the desired range, although with great variations mainly in CG and relatives of both groups. In general, there is evidence that acute and strenuous exercise may increase lipid peroxidation, but regular physical training may also increase the power of antioxidants (40). In our series, all the footballers presented with reference levels with a lower mean in relation to the other groups. This may be due to the aggravated antioxidant capacity, which should be further investigated.

Moreover, this study showed there was a strong association between higher MDA concentrations, obesity, and sedentary life style, as confirmed by multivariate logistic regression analysis. Thus, all CG, $90.9 \%$ of RFG and $63.6 \%$ of RCG who presented increased MDA levels were also sedentary (data not shown). This fact reinforces the controversy about the real association between physical exercise and oxidative stress (12). In this context, Ji (13) suggests that intensive and currently aerobic physical exercising can stimulate the synthesis of free radicals and consequently lesions of the muscle fibers of athletes, fatigue, alterations in the immune system, and reductions in physical performance. On the other hand, Watson and cols. (40) report that this damage may be prevented by optimizing nutrient intake, particularly by dietetic supplementation considering 
antioxidants agents such as vitamins (beta carotene, tocopherol, and ascorbic acid) and minerals (zinc).

In summary, these results suggest there is an association between endurance exercise training and lower levels of MDA in professional footballers, although without influence on lipid profile compared to controls. Moreover, physical activity seems to promote beneficial effects on lipid profile in spite of genetic influence, principally in respect to HDLc levels.

Disclosure: no potential conflict of interest relevant to this article was reported.

\section{REFERENCES}

1. De Matos LD, Caldeira ND, Perlingeiro PD, Dos Santos IL, Negrao $\mathrm{CE}$, Azevedo LF. Cardiovascular risk and clinical factors in athletes: ten years of evaluation. Med Sci Sports Exerc. 2010 [Epub ahead of print]. doi: 10.1249/MSS.0b013e318203d5cb.

2. Bye A, Tjønna AE, Stølen TO, Røsbjørgen RE, Wisløff U. Transcriptional changes in blood after aerobic interval training in patients with the metabolic syndrome. Eur J Cardiovasc Prev Rehabil. 2009;16:47-52.

3. Leon AS, Sanchez OA. Response of blood lipids to exercise training alone or combined with dietary intervention. Med Sci Sports Exerc. 2001;33:S502-15.

4. Kishali NF, Imamoglu O, Kaldirimci M, Akyol P,Yildirim K. Comparison of lipid and lipoprotein values in men and women differing in training status. Int J Neurosci. 2005;115:1247-57.

5. Hoekstra T, Boreham CA, Murray LJ, Twisk JW. Associations between aerobic and muscular fitness and cardiovascular disease risk: the northern Ireland young hearts study. J Phys Act Health. 2008:5:815-29.

6. Kraus WE, Houmard JA, Duscha BD, Knetzger KJ, Wharton MB, McCartney JS, et al. Effects of the amount and intensity of exercise on plasma lipoproteins. N Engl J Med. 2002;347:1483-92.

7. Katzmarzyk PT, Leon AS, Rankinen T, Gagnon J, Skinner JS, Wilmore $\mathrm{JH}$, et al. Changes in blood lipids consequent to aerobic exercise training related to changes in body fatness and aerobic fitness. Metabolism. 2001;50:841-8.

8. Thompson PD, Crouse SF, Goodpaster B, Kelley D, Moyna N, Pescatello $\mathrm{L}$. The acute versus the chronic response to exercise. Med Sci Sports Exerc. 2001;33:S438-45.

9. Lippi G, Schena F, Salvagno GL, Montagnana M, Ballestrieri F, Guidi GC. Comparison of the lipid profile and lipoprotein(a) between sedentary and highly trained subjects. Clin Chem Lab Med. 2006;44:322-6.

10. Hernández-Torres RP, Ramos-Jiménez A, Torres-Durán PV, Romero-Gonzalez J, Mascher D, Posadas-Romero C, et al. Effects of single sessions of low-intensity continuous and moderate-intensity intermittent exercise on blood lipids in the same endurance runners. J Sci Med Sport. 2009;12:323-31.

11. Bloomer RJ, Goldfarb AH. Anaerobic exercise and oxidative stress: a review. Can J Appl Physiol. 2004;29:245-63.

12. Valko M, Leibfritz D, Moncol J, Cronin MT, Mazur M, Telser J. Free radicals and antioxidants in normal physiological functions and human disease. Int J Biochem Cell Bi. 2007;39:44-84.

13. Ji LL. Exercise at old age: does it increase or alleviate oxidative stress. Ann NY Acad Sci. 2001;928:236-47.

14. Yang RL, ShiYH, Hao G, LiW, Le GW. Increasing oxidative stress with progressive hyperlipidemia in human: relation between malondialdehyde and atherogenic index. J Clin Biochem Nutr. 2008;43:154-8.

15. Parra FC, Amado RC, Lambertucci JR, Rocha J, Antunes CM, Pena SD. Color and genomic ancestry in Brazilians. Proc Natl Acad Sci U S A. 2003;100:177-82.

16. Bucolo G, David H. Quantitative determination of serum triglycerides by the use of enzymes. Clin Chem. 1973;19:476-82.

17. Allain CC, Poon LS, Chan CS, Richmond W, Fu PC. Enzymatic determination of total serum cholesterol. Clin Chem. 1974;20:470-5.
18. Friedewald WT, Levy RI, Fredrickson DS. Estimation of the concentration of low-density lipoprotein cholesterol in plasma, without use of the preparative ultracentrifugation. Clin Chem. 1972;18:499-502.

19. Santos RD and Sociedade Brasileira de Cardiologia. III Brazilian Guidelines on Dyslipidemias and Guideline of Atherosclerosis Prevention from Atherosclerosis Department of Sociedade Brasileira de Cardiologia. Arq Bras Cardiol. 2001;77:1-48.

20. Genuth S, Alberti KG, Bennett P, Buse J, Defronzo R, Kahn R, et al. Follow-up report on the diagnosis of diabetes mellitus. Diabetes Care. 2003;26:3160-7.

21. Liu J, Yeo HC, Doniger SJ, Ames BN. Assay of aldehydes from lipid peroxidation: gas chromatography-mass spectrometry compared to thiobarbituric acid. Anal Biochem. 1997;245:161-6.

22. Marcovina SM, Albers JJ, Henderson LO, Hannon WH. International Federation of Clinical Chemistry standardization project for measurements of apolipoproteins A-I and B. III comparability of apolipoprotein A-I values by use of international reference material. Clin Chem. 1993;39:773-8.

23. Clinical guidelines on the identification, evaluation, and treatment of overweight and obesity in adults: executive summary. Expert Panel on the Identification, Evaluation, and Treatment of Overweight in Adults. Am J Clin Nutr. 1998;68:899-917.

24. Petridou A, Lazaridou D, Mougios V. Lipidemic profile of athletes and non-athletes with similar body fat. Int J Sport Nutr Exerc Metab. 2005;15:425-32.

25. Heitkamp HC, Wegler S, Brehme U, Heinle H. Effect of an 8-week endurance training program on markers of antioxidant capacity in women. J Sports Med Phys Fitness. 2008;48:113-9.

26. Jafari $M$, Leaf DA, Macrae $H$, Kasem J, O'conner P, Pullinger $C$, et al. The effects of physical exercise on plasma prebeta-1 high-density lipoprotein. Metabolism. 2003;52:437-42.

27. Ribeiro IC, Iborra RT, Neves MQ, Lottenberg SA, Charf AM, Nunes VS, et al. HDL atheroprotection by aerobic exercise training in type 2 diabetes mellitus. Med Sci Sports Exerc. 2008;40(5):779-86.

28. Carvalho J, Marques E, Ascensão A, Magalhães J, Marques $F_{1}$ Mota J. Multicomponent exercise program improves blood lipid profile and antioxidant capacity in older women. Arch Gerontol Geriatr. 2010;51:1-5.

29. Feitosa MF, Rice T, Rankinen T, Almasy L, Leon AS, Skinner JS, et al. Common genetic and environmental effects on lipid phenotypes: the HERITAGE family study. Hum Hered. 2005;59:34-40.

30. Rice T, Després JP, Pérusse $L$, Hong $Y$, Province MA, Bergeron J, et al. Familial aggregation of blood lipid response to exercise training in the health, risk factors, exercise training, and genetics (HERITAGE) Family Study. Circulation. 2002;105:1904-8.

31. Laursen PB, Rhodes EC. Factors affecting performance in an ultraendurance triathlon. Sports Med. 2001; 31:195-209.

32. Burke LM, Kiens B, Ivy JL. Carbohydrates and fat for training and recovery. J Sports Sci. 2004;22:15-30.

33. Parks EJ. Effect of dietary carbohydrate on triglyceride metabolism in humans. J Nutr. 2001;131:2772S-2774S.

34. Fried SK, Rao SP. Sugars, hypertriglyceridemia, and cardiovascular disease. Am J Clin Nutr. 2003;78:873S-80S.

35. McCarty MF. An elevation of triglycerides reflecting decreased triglyceride clearance may not be pathogenic - relevance to high-carbohydrate diets. Med Hypotheses. 2004;63:1065-73.

36. Tseng $\mathrm{CH}$, Tseng $\mathrm{CP}$, Chong CK, Cheng JC, Tai TY. Independent association between triglycerides and coronary artery disease in Taiwanese type 2 diabetic patients. Int J Cardiol. 2006;111:80-5.

37. Parks EJ, Hellerstein MK. Carbohydrate-induced hypertriacylglycerolemia: historical perspective and review of biological mechanisms. Am J Clin Nutr. 2000;71:412-33.

38. Tirosh A, Shai I, Tekes-Manova D, Israeli E, Pereg D, Shochat T, et al. Normal fasting plasma glucose levels and type 2 diabetes in young men. N Engl J Med. 2005;353:1454-62.

39. Kumari SS, Menon VP. Changes in concentration of lipid peroxides and activities of superoxide dismutase and catalase in isoproterenol induced myocardial infarction in rats. Indian J Exp Biol. 1987;25:419-23.

40. Watson TA, Callister R, Taylor RD, Sibbritt DW, Macdonald-Wicks LK, Garg ML. Antioxidant restriction and oxidative stress in short-duration exhaustive exercise. Med Sci Sports Exerc. 2004;37:63-71. 